\title{
Pattern and microbiological characteristics of diabetic foot ulcers in a Nigerian tertiary hospital
}

Obumneme Anyim ${ }^{1}$, Christian Okafor ${ }^{2}$, Ekenechukwu Young ${ }^{2}$, Ijeoma Obumneme-Anyim ${ }^{3}$, Chidimma Nwatu ${ }^{2}$

1. Department of Medicine, Enugu State University of Science \& Technology Teaching Hospital, Parklane, Enugu, Enugu State, Nigeria.

2. Endocrine Unit, Department of Medicine, University of Nigeria / University of Nigeria Teaching

Hospital, Ituku-Ozalla, Enugu State, Nigeria;

3. Department of Paediatrics, University of Nigeria Teaching Hospital, Ituku-Ozalla, Enugu State, Nigeria.

\begin{abstract}
:
Purpose: To determine the pattern and bacteriological characteristics of diabetic foot ulcers in patients attending a tertiary health care facility.
\end{abstract}

Method: 160 Patients with Diabetes Mellitus foot syndrome were recruited, out of which 52 had diabetic foot ulcers. Relevant clinical, biochemical, and microbiological evaluations were carried out on the subjects. Data analysis was done using SPSS version 20. p value was set at $<0.05$.

Results: 52 (32.5\%) out of 160 subjects with Diabetes Mellitus Foot Syndrome (DMFS) had diabetic foot ulcers. Poor glycaemic control (mean HbA1c $=9.2(2.7) \%$ ), and abuse of antibiotics $(76.9 \%)$ characterized the subjects. Foot ulcers mainly involved the right lower limb and followed spontaneous blister formation (50\%). Microbiological culture pattern was polymicrobial (71.2\%); predominantly anaerobic organisms (53.3\%). Gram positive and negative aerobic isolates yielded high sensitivity to common quinolones $(76 \%-87.8 \%)$. The gram positive and negative anaerobic isolates were highly sensitive to Clindamycin and Metronidazole respectively $(80.2 \%-97.8 \%)$. High sensitivity $(>80 \%)$ yield for gram negative anaerobes was recorded for Imipinem and Ampicillin/Sulbactam.

Conclusion: Diabetic foot ulcers (DFU) contribute about one-third of DMFS. The bacteriological isolates from these ulcers are mainly polymicrobial with high sensitivity to common antibiotics. The need for appropriate use of antibiotics should be advocated among the patients.

Keywords: Diabetes mellitus, antibiotic sensitivity, Nigeria.

DOI: https://dx.doi.org/10.4314/ahs.v19i1.37

Cite as: Anyim O, Okafor C, Young E, Obumneme-Anyim I, C N. Pattern and microbiological characteristics of diabetic foot ulcers in a Nigerian tertiary hospital. Afri Health Sci. 2019;19(1). 1617-1627. bttps://dx.doi.org/10.4314/abs.v19i1.37

\section{Introduction}

Many complications affect people living with diabetes mellitus (DM), of which diabetic mellitus foot syndrome (DMFS) is one of the most devastating and indeed seems

\section{Corresponding author:}

Christian Okafor, Department of Medicine, University of Nigeria / University of Nigeria Teaching Hospital, Ituku-Ozalla, Enugu, Nigeria.

Email: christian.okafor@unn.edu.ng to be a common cause of prolonged hospitalization. The costs associated with diabetic foot ulcers (DFUs) can be tremendous for the patient, the family, the health care system and the society at large. ${ }^{1}$

Available evidences on DMFS show that the outcomes have not changed much in the past 30 years, despite huge advances in the medical and surgical treatment of patients with diabetes. ${ }^{2}$

More than 80,000 amputations are performed yearly on diabetic patients in the United States, and approximately $50 \%$ of the people with amputations will develop ulcer-

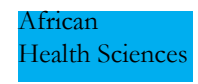

(C) 2019 Anyim et al. Licensee African Health Sciences. This is an Open Access article distributed under the terms of the Creative commons Attribution License (https://creativecommons.org/licenses/BY/4.0), which permits unrestricted use, distribution, and reproduction in any medium, provided the original work is properly cited. 
ations and infections in the contralateral limb within 18 months. An alarming 58\% will have a contralateral amputation 3-5 years after the first amputation while the 3-year mortality after a first amputation has been estimated to be as high as $20-50 \% .^{2}$

In Nigeria, it was observed that more males in their prime presented with DMFS than females. ${ }^{1}$ The average cost of managing a single ulcer is about $\$ 8,000$, and with infection, the cost rises to about $\$ 17,000 .^{2}$ When it involves a major amputation, it further rises to $\$ 45,000 .^{2}$ Ogbera et $\mathrm{al}^{3}$ in Nigeria (Lagos) about a decade ago found the mean cost for successfully treating a patient with DMFS to be Nigerian Naira (NGN) 180, 581.60 (equivalent to US $\$ 1,389.83$ at $1 \mathrm{USD}=\mathrm{NGN} 129.93$ using the exchange rate as at when the study was done). The total costs incurred ranged from NGN 20,400.00 (US\$157.00.) to NGN 278,029.00 (US\$2,139.84). With worsening inflation rates, these values would have increased, and with the present exchange rate (1USD to NGN 306), the mean cost for successfully treating a patient with DMFS would be estimated to stand at NGN425,287.98. The National Bureau of Statistics of Nigeria had in February 2012 released figures that showed that about 112 million Nigerians $(67.1 \%$ of the country's total population of 167 million) lived below poverty level-that is living below US $\$ 1.00-U S \$ 1.25$ per day. ${ }^{4}$ This would place the cost of caring for DMFS beyond the reach of the average Nigerian. In addition to the direct costs of treatment, it is important to remember the indirect costs relating to loss of productivity, loss of quality of life and sometimes mortality.

Two hospital-based studies in Nigeria have demonstrated that diabetic foot disease accounted for the majority of non-traumatic amputations performed, ranging from $22.3 \%$ to $29.3 \%$. ${ }^{5,6}$ The combination of neuropathy, ischaemia and direct adverse effects of DM on hosts defense mechanisms make patients with diabetes particularly vulnerable to foot infections and gangrene; often resulting in limb loss. ${ }^{7}$ Foot infections in diabetic patients are usually polymicrobial. ${ }^{8}$ Staphylococcus aureus was the commonest isolate reported in some Nigerian studies. ${ }^{9-11}$ Early identification of the foot at risk for ulceration would prompt early and effective treatment. Moreover, bacteriological and sensitivity patterns change and there is a need for periodic studies to keep abreast with these changes.
Since microbial culture and antibiotic sensitivity results cannot be generated in less than 48 hours (and may, on some occasions, take considerably longer), a knowledge of the antimicrobial sensitivity pattern of most bacteriological isolates in the locality would be helpful in deriving early empirical antimicrobial therapy for diabetic limb infections. This may help to reduce the socio-economic burden of the disease, amputation rates and mortality among diabetic patients.

The aim of this study was therefore to determine the burden and bacteriological characteristics of diabetic foot ulcers seen in patients attending our tertiary health care facility at Enugu, Nigeria.

\section{Materials and methods}

This was a cross-sectional descriptive hospital-based study performed over a six months period from November 2013 to April 2014 at the University of Nigeria Teaching Hospital, Enugu. Over this period, a total of 1,597 patients with diabetes mellitus were seen.

Patients were selected from the Diabetes Clinic attendance and Ward admission registers based on fulfilling the following criteria: age $\geq 18$ years, presence of DMFS (either diabetic foot at risk, (including evidence of neuropathy and peripheral vascular disease) and / or foot ulceration, gangrene or amputation) after detailed examination, and giving of consents. Detailed examination outside clinical evaluation, involved examination using 10-g Semmes-Weinstein monofilament (SenSitest Monofilament, ES-A58.426.677), biothesiometer (Bio-medical instrument Co., Newbury, Ohio, USA) and a Hand held Eden ultrasonic pocket Doppler (Shanghai International holding corp. GmbH, Shanghai, China). 160 patients who fulfilled the criteria above were consecutively enrolled into the study.

Ethical approval was obtained from the Health Research Ethics Committee of the Teaching Hospital.

A structured pre-tested questionnaire was administered to the consenting patients by the investigators and trained assistants. This assessed information such as age, sex, occupation, presence of hypertension, duration of diabetes, smoking, features of peripheral vascular disease (intermittent claudication, cold feet and rest pain), features of neuropathy, duration of lower limb ulceration, and history of previous amputation. Out of the 160 subjects, 52 $(32.5 \%)$ subjects were identified to have DFU(s) which 
were now further evaluated clinically and microbiologically. These ulcers were graded using both the University Of Texas Classification of Diabetic Foot and Wagner's classification system. Ulcers were assessed for signs of infection (swelling, exudates, surrounding, cellulitis, odour, tissue necrosis and crepitation) Plain radiograph was performed on all the subjects with limb ulcer to assess for osteomyelitis.

\section{Microbiological procedure}

Two sets of deep wound samples were obtained by rolling two sterile swab sticks one after the other over the surface of the sampling site, after debridement of superficial exudates. One swab specimen was immediately transferred into a thioglycollate medium, and sent with the second specimen to the microbiology laboratory for analysis under the supervision of a Medical Microbiologist. Samples were inoculated into Robertson's cooked meat media, and were incubated at $37^{\circ} \mathrm{C}$ for 48 hours. Sub-cultures were made from the Robertson's cooked media into different media using standard wire loop. For aerobic cultures, subcultures were made from the top of Robertson's medium into sheep blood agar and MacConkey agar and incubated at $37^{\circ} \mathrm{C}$ for 24 hours. For anaerobic cultures, sub-cultures were made onto Rogosa agar and anaerobic basal agar (Oxoid CM0972) supplemented with 5\% horse blood. The medium was inoculated by surface plating to obtain single colonies. These were incubated in anaerobic jar at $37^{\circ} \mathrm{C}$ for a minimum of 72 hours. Anaerobic condition was achieved using the Oxoid AnaroGen Atmosphere Generation System (AN0025)®. Anaerobiosis was monitored with the help of a biological indicator (failure of growth of pure isolate of Pseudomonas aeruginosa, a strict aerobe) and a chemical indicator (methylene blue).

The jar was opened after 72 hours. The plates were examined with the help of a hand lens and each colony type recorded. Each type of colony was picked and sub-cultured onto Columbia blood agar for purity anaerobically. If no growth was obtained after 72 hours then re-incubation was done for at least 7 days after which if still no growth, a negative report was then given.

Colony characteristics were noted in case of any growth. Identification of micro-organisms was done using Gram stain and other biochemical tests from Columbia blood agar and Gram stain.

The isolated organisms were inoculated onto blood agar plates and anti-microbial susceptibility testing was carried out using the modified Kirby-Bauer disc diffusion method. ${ }^{12}$ Discs for available, anti-microbial agents were used. Attempts were made to incorporate discs representative of different classes of anti-microbials. Disc of the following anti-microbials were used: Ceftriaxone $(30 \mu \mathrm{g})$,

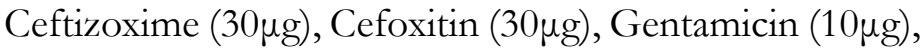
Amoxicillin/Clavulanate $(30 \mu \mathrm{g})$, Cefuroxime $(30 \mu \mathrm{g})$, Nitrofurantoin $(100 \mu \mathrm{g})$, Ceftazidime $(30 \mu \mathrm{g})$, Ciprofloxacin $(10 \mu \mathrm{g})$, Ofloxacin $(10 \mu \mathrm{g})$, Pefloxacine $(30 \mu \mathrm{g})$, Clindamycin $(2 \mu \mathrm{g})$, Ampicillin/Sulbactam $(10 / 10 \mu \mathrm{g})$, Imipenem $(10 \mu \mathrm{g})$, Clarithromycin $(10 \mu \mathrm{g})$, Ampicillin $(30 \mu \mathrm{g})$, Erythromycin $(10 \mu \mathrm{g})$, Ampicillin/Cloxacillin $(30 \mu \mathrm{g})$, Cefixime $(5 \mu \mathrm{g})$, Levofloxacin $(10 \mu \mathrm{g})$, Norfloxacin $(10 \mu \mathrm{g})$, And Metronidazole $(5 \mu \mathrm{g})$. Following overnight incubation, the culture was examined for areas of no growth around the discs (zones of inhibition). The anti-microbial sensitivity pattern for different bacterial isolates were documented.

\section{Data analysis}

Data analysis was done using Statistical Package for the Social Sciences (SPSS) version 20 (IBM Corp, 2011. Armonk, NY) Qualitative data were described as proportions or percentages, cross tabulation was used where necessary. Quantitative data were reported as mean and standard deviation, or as median and inter-quartile range in case of a skewed distribution. Test of significance for differences for quantitative and categorical variables were tested with T-test and Chi square analyses respectively. A $\mathrm{p}$ value of $<0.05$ was considered as significant.

\section{Results}

\section{General characteristics of study population}

Subjects with DFU were 52 (26 male and 26 female participants respectively) out of 160 with DMFS. DFU therefore contributed $32.5 \%$ of DMFS among these subjects. The age range of the participants was 40 to 89 years. The age group with the highest number of participants was $41-60$ years $(57.7 \% ; 30 / 52)$. The mean age at diagnosis of DM was $47.8 \pm 12.7$ years while the mean duration of DM was $11.5 \pm 7.3$ years. Some of their characteristics are presented in Table 1. According to Table 1, male participants were older but diagnosis of diabetes mellitus was significantly earlier in females. Systolic blood pressure (SBP), and obesity (generalized and central) was commoner among the females. Glycaemic control was generally poor and had no significant gender difference. Majority were traders, and only able to attain primary education but these were not significantly associated with gender. 
Table 1: Biochemical, Socio-demographic and anthropometric characteristics of the study population

\begin{tabular}{|c|c|c|c|c|}
\hline \multirow[b]{2}{*}{ Characteristics } & \multicolumn{3}{|c|}{ Mean (SD) } & \multirow[b]{2}{*}{ Pvalue } \\
\hline & $\begin{array}{l}\text { Males } \\
(n=26)\end{array}$ & $\begin{array}{c}\text { Females } \\
(n=26)\end{array}$ & $\begin{array}{l}\text { Total } \\
(n=52)\end{array}$ & \\
\hline Age (years) & $61.7(9.7)$ & $58.1(11)$ & $59.9(10.5)$ & 0.221 \\
\hline Age at diagnosis of DM (years) & $52.6(11.5)$ & $43(12.1)$ & $47.8(12.7)$ & $0.005^{*}$ \\
\hline Duration of DM (years) & $9.5(7.7)$ & $13.6(6.3)$ & $11.5(7.3)$ & $0.043^{*}$ \\
\hline $\mathrm{BMI}\left(\mathrm{kg} / \mathrm{m}^{2}\right)$ & $24.2(4.4)$ & $28.5(4.9)$ & $26.4(5.1)$ & $0.005^{*}$ \\
\hline $\mathrm{WC}(\mathrm{cm})$ & $88.8(11.1)$ & $96.6(9.8)$ & $92.8(11.1)$ & $0.019^{*}$ \\
\hline $\mathrm{SBP}(\mathrm{mmHg})$ & $129.8(12.9)$ & $146(25.4)$ & $137.9(21.6)$ & $0.006^{*}$ \\
\hline $\mathrm{DBP}(\mathrm{mmHg})$ & $79.2(12)$ & $82.7(10.5)$ & $81(11.3)$ & 0.268 \\
\hline FPG (mmol/L) & $13.1(5.9)$ & $10.2(6.2)$ & $11.7(6.2)$ & 0.089 \\
\hline \multirow[t]{2}{*}{$\operatorname{HbA} 1 \mathrm{c}(\%)$} & $9.7(2.5)$ & $8.7(2.9)$ & $9.2(2.7)$ & 0.192 \\
\hline & \multicolumn{2}{|c|}{ N (\% within gender) } & $\mathbf{N}(\%$ of total) & \\
\hline \multicolumn{5}{|l|}{ Occupation } \\
\hline Traders & $13(50)$ & $9(34.6)$ & $22(42.3)$ & \\
\hline Civil servant & $2(7.7)$ & $7(26.9)$ & $9(17.3)$ & \\
\hline Farmers & $3(11.5)$ & $4(15.4)$ & $7(13.5)$ & \\
\hline Retired civil servants & $3(11.5)$ & $3(11.5)$ & $6(11.5)$ & \\
\hline Artisans & $5(19.2)$ & - & $5(9.6)$ & 0.386 \\
\hline Unemployed & - & $3(11.5)$ & $3(5.8)$ & \\
\hline \multicolumn{5}{|l|}{ Educational Status } \\
\hline Nil & $1(3.8)$ & $2(7.7)$ & $3(5.8)$ & \\
\hline Primary & $14(53.8)$ & $12(46.2)$ & $26(50)$ & 0.26 \\
\hline Secondary & $7(26.9)$ & $3(11.5)$ & $10(19.2)$ & \\
\hline Tertiary & $4(15.4)$ & $9(34.6)$ & $13925)$ & \\
\hline
\end{tabular}

\section{Characterization of foot ulcers}

Wagner's grade 1 was the commonest grade of ulcer among the participants. The right lower limb was the more commonly affected of the two limbs (29/52 (55.8\%)).
Radiological features of osteomyelitis were present in $11(21.2 \%)$ of the participants and they all had a Wagner ulcer grade between 3 and 5. Table 2 below shows the distribution of the ulcers according to Wagner's grading.

Table 2: Wagner's distribution of the DFU among the participants

\begin{tabular}{rlll}
\hline $\begin{array}{l}\text { Wagner's } \\
\text { Grade }\end{array}$ & Description of the ulcer & Frequency & Percent \\
\hline $\mathbf{1}$ & Superficial ulcers & 17 & 32.7 \\
$\mathbf{2}$ & Deep ulcers & 16 & 30.8 \\
$\mathbf{3}$ & Ulcer with bone involvement & 12 & 23.1 \\
$\mathbf{4}$ & Forefoot gangrene & 4 & 7.7 \\
$\mathbf{5}$ & Whole foot gangrene & 3 & 5.8 \\
\cline { 2 - 4 } & Total & $\mathbf{5 2}$ & 100.0 \\
\hline
\end{tabular}


Among the causes of the ulcers as shown in Figure 1, spontaneous blisters was the commonest. The median duration of ulcer before hospital presentation was 6.5 (0.4-52.0) weeks. Forty $(76.9 \%)$ individuals with DFU had received antibiotics before presentation. Ampicillin/ Cloxacillin was the most common drug used by these individuals $(30 \%(12 / 40))$. Thirty-one $(59.6 \%)$ of them had the last dose of antibiotic more than a week before recruitment into the study.

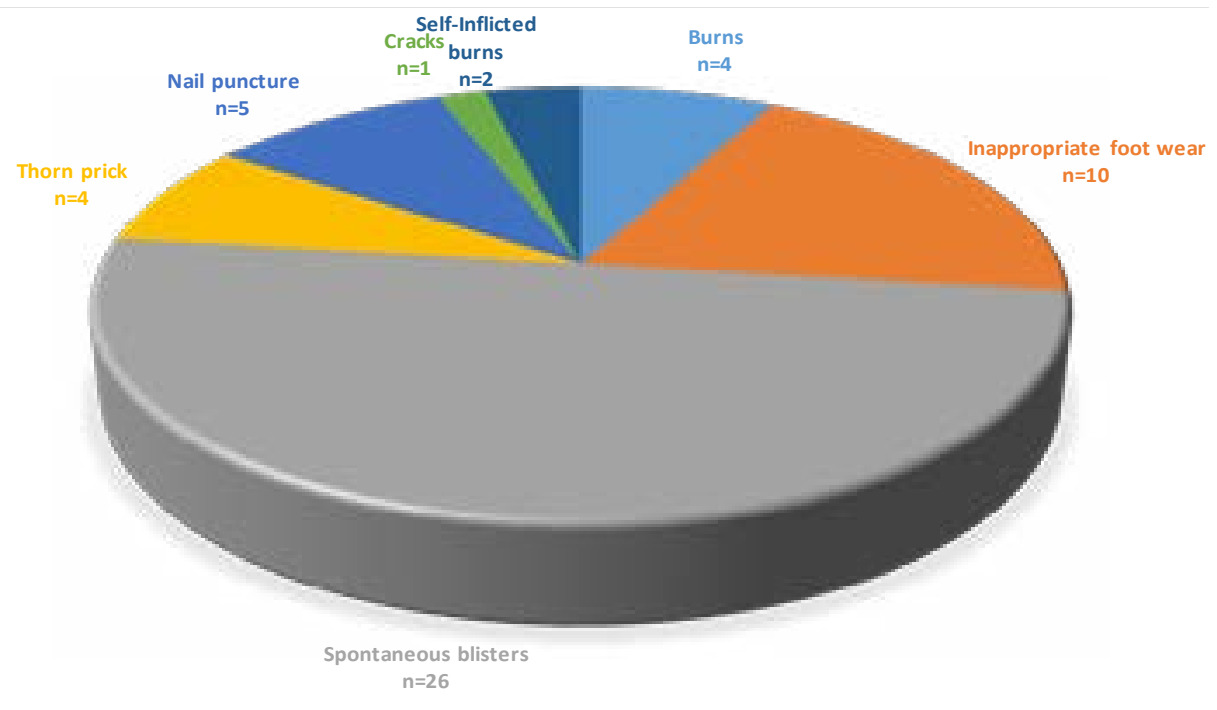

Figure 1: Distribution of causes of ulcer among study participants

Pattern of bacteriological flora in the participants with diabetic foot ulcers

A total of 137 organisms were isolated from the participants. Approximately $71.2 \%$ were polymicrobial. Sev- en percent grew only anaerobes, $5.8 \%$ only aerobes and $15.4 \%$ were sterile cultures. The various types and frequencies of the isolated organisms are shown in Table 3 with anaerobes constituting a greater majority of the isolated organisms $(53.3 \%(73 / 137))$.

Table 3: Types and frequencies of isolated organisms

\begin{tabular}{lll}
\hline \hline Types of isolated organisms & Frequency & Percent \\
\hline Aerobes & & \\
Corynebacterium spp & 9 & 14.1 \\
Proteus mirabilis & 9 & 14.1 \\
Pseudomonas aeruginosa & 8 & 12.5 \\
Staphylococcus aureus & 11 & 17.2 \\
Coagulase negative Staphylococcus aureus & 2 & 3.1 \\
Streptococcus pyogenes & 10 & 15.6 \\
Enterococcus faecalis & 4 & 6.3 \\
Escherichia coli & 6 & 9.4 \\
Klebsiellae pneumoniae & 4 & 6.3 \\
Morganella spp & 1 & 1.6 \\
Total & $\mathbf{6 4}$ & $\mathbf{1 0 0}$ \\
Anaerobes & & \\
Propionibacterium spp & 13 & 17.8 \\
Bacteroides spp & 21 & 28.8 \\
Eubacterium spp & 2 & 2.7 \\
Peptostreptococcus spp & 15 & 20.5 \\
Fusobacterium spp & 7 & 9.6 \\
Prevotella spp & 6 & 8.2 \\
Closteridium spp & 4 & 5.5 \\
Lactobacillus & 1 & 1.4 \\
Anaerococcus spp & 4 & 5.5 \\
Total & $\mathbf{7 3}$ & $\mathbf{1 0 0}$ \\
\hline
\end{tabular}


Susceptibility pattern of the isolated organisms

The susceptibility pattern of the isolated bacteria revealed that the gram positive aerobic organisms showed

high sensitivity to levofloxacin and Norfloxacin while ma- jority of the Gram negative aerobes were highly sensitive to Pefloxacin and Ciprofloxacin (Table 4). The highest sensitivity for anaerobes was recorded for clindamycin and metronidazole (Table 5).

Table 4: Susceptibility pattern of isolated aerobic organisms

\begin{tabular}{|c|c|c|c|c|c|c|c|c|c|c|}
\hline \multirow[b]{2}{*}{ Gram positive } & \multicolumn{10}{|c|}{ "Susceptibility pattern (\%) } \\
\hline & Eryth & Ceft & $\mathrm{A} / \mathrm{Cx}$ & Cef & Levo & Norf & Gent & Oflo & Clin & Cipr \\
\hline Corynebacterium & 100 & 100 & 55.6 & 100 & 100 & 100 & 55.6 & 77.8 & 77.8 & 77.8 \\
\hline $\begin{array}{l}\text { spp } \\
\text { Staphylococcus } \\
\text { aureus }\end{array}$ & 54.5 & 54.5 & 54.5 & 54.5 & 100 & 100 & 54.5 & 27.3 & 54.5 & 72.7 \\
\hline $\begin{array}{l}\text { Coagulase } \\
\text { negative } \\
\text { Staphylococcus } \\
\text { aureus }\end{array}$ & 100 & - & - & - & 100 & 100 & - & - & - & 100 \\
\hline $\begin{array}{l}\text { Streptococcus } \\
\text { pyogenes }\end{array}$ & 60.0 & 60.0 & 40.0 & ND & 80 & 60.0 & 40.0 & 40.0 & 60.0 & 80.0 \\
\hline $\begin{array}{l}\text { Enterococcus } \\
\text { faecalis }\end{array}$ & - & 50.0 & - & - & 50 & 50.0 & 50.0 & - & 50.0 & 50.0 \\
\hline Total \% & 314.5 & 264.5 & 150.1 & 154.5 & 430 & 410 & 200.1 & 145.1 & 242.3 & 380.5 \\
\hline Mean \% & 62.9 & 52.9 & 30.0 & 38.6 & 86.0 & 82.0 & 40.0 & 29.0 & 48.5 & 76.1 \\
\hline Gram negative & Nitro & Ceft & Cipr & Gent & Oflo & $\mathrm{A} / \mathrm{Cv}$ & Pef & Clar & Chlo & Amp \\
\hline Proteus & - & 55.6 & 88.9 & 55.6 & 22.2 & & & & & \\
\hline mirabilis & & & & & & 205.5 & 438.9 & 83.3 & 183.3 & 33.3 \\
\hline Mean \% & 23.3 & 37.8 & 87.8 & 61.1 & 39.4 & 41.1 & 87.8 & 16.7 & 36.7 & 8.3 \\
\hline $\begin{array}{l}\text { (Eryth) Erythromyci } \\
\text { (Norf) Norfloxacin, } \\
\text { Nitrofurantoin, (A/C } \\
\text { (Amp) Ampicillin, ( } \\
\text { NR. Blank cells }=0^{0}\end{array}$ & $\begin{array}{l}\text { (Ceft } \\
\text { Jent) } \\
\text { Amo } \\
\text { not }\end{array}$ & $\begin{array}{l}\operatorname{triaxc} \\
\text { amyc } \\
\text { a/Cla }\end{array}$ & $\begin{array}{l}\overline{(\mathrm{A} / \mathrm{C}} \\
\text { (Oflc } \\
\text { nate, }\end{array}$ & $\begin{array}{l}\text { Ampic } \\
\text { Ofloxac } \\
\text { ef) Pef }\end{array}$ & $\mathrm{n} / \mathrm{Clox}$ & $\begin{array}{l}\text { illin, } \\
\text { Clind } \\
\text { ar) } \mathrm{Cl}\end{array}$ & $\begin{array}{l}\text { ef) } \mathrm{Ce} \\
\text { aycin, } \\
\text { thromy }\end{array}$ & $\begin{array}{l}\text { sime, } \\
\text { ipr) C } \\
\text { n, (Ch }\end{array}$ & $\begin{array}{l}\text { vo) Le } \\
\text { ofloxac } \\
\text { Chlora }\end{array}$ & $\begin{array}{l}\text { loxacin, } \\
\text { (Nitro) } \\
\text { henicol, }\end{array}$ \\
\hline
\end{tabular}


Table 5: Susceptibility pattern of isolated anaerobic organisms

\begin{tabular}{llllllllll}
\hline Gram positive & \multicolumn{7}{c}{ Susceptibility pattern (\%) } \\
\cline { 2 - 10 } & A/S & Clin & Imip & Ceft & Ceftiz & Metro & Cefo & Amp & Pen \\
\hline Propionibacterium spp & 76.9 & 84.6 & ND & 76.9 & 53.8 & 100 & 76.9 & 84.6 & 84.6 \\
Peptostreptococcus spp & 73.3 & 100 & ND & 73.3 & 53.3 & 86.7 & 73.3 & 53.3 & 40.0 \\
Anaerococcus spp & 100 & 100 & ND & 50.0 & 50.0 & 100 & 50.0 & 50.0 & 50.0 \\
Closteridium spp & 50.0 & 100 & ND & 50.0 & 50.0 & 100 & 50.0 & 100 & 100 \\
Eubacterium spp & 100 & 100 & ND & - & 100 & 100 & - & - & - \\
Lactobacillus spp & - & 100 & ND & - & - & 100 & - & - & 100 \\
Total \% & 400.2 & 584.6 & 0 & 250.2 & 307.1 & 586.7 & 250.2 & 287.9 & 374.6 \\
Mean \% & 66.7 & 97.4 & 0.0 & 41.7 & 51.2 & 97.8 & 41.7 & 48.0 & 62.4 \\
Gram negative & & & & & & & & & \\
Bacteroides spp & 90.5 & 90.5 & 90.5 & 62.0 & 71.4 & 90.5 & 52.4 & ND & ND \\
Prevotella spp & 100 & 100 & 50.0 & - & - & 50.0 & - & - & - \\
Fusobacterium spp & 71.4 & 100 & 100 & 71.4 & 71.4 & 100 & 71.4 & 100 & $\mathbf{7 1 . 4}$ \\
Total \% & $\mathbf{2 6 1 . 9}$ & $\mathbf{2 9 0 . 5}$ & $\mathbf{2 4 0 . 5}$ & $\mathbf{1 3 3 . 4}$ & $\mathbf{1 4 2 . 8}$ & $\mathbf{2 4 0 . 5}$ & $\mathbf{1 2 3 . 8}$ & $\mathbf{1 0 0}$ & $\mathbf{7 1 . 4}$ \\
Mean \% & $\mathbf{8 7 . 3}$ & $\mathbf{9 6 . 8}$ & $\mathbf{8 0 . 2}$ & $\mathbf{4 4 . 5}$ & $\mathbf{4 7 . 6}$ & $\mathbf{8 0 . 2}$ & $\mathbf{4 1 . 3}$ & $\mathbf{5 0 . 0}$ & $\mathbf{3 5 . 7}$ \\
\hline
\end{tabular}

[(A/S) Ampicillin/Sulbactam, (Clin) Clindamycin, (Imip) Imipenem, (Ceft) Ceftriaxone (Ceftiz)

Ceftizoxime, (Metro) Metronidazole, (Cefo) Cefoxitin, (Amp) Ampicillin, (Pen) Penicillin, (ND) not

done] NB: Blank cells $=0 \%$

\section{Discussion}

Diabetic Foot Ulcerations constituted about a third of the burden of foot lesions in the participants who were a subset of patients with DMFS. This clear demonstration of the huge burden and challenge among Nigerians suffering from complications of diabetes mellitus is similar to the high prevalence of $37.2 \%$ reported by Ajayi et $\mathrm{al}^{13}$ in Ido Ekiti Nigeria. It is also comparable to other findings in Africa and beyond. ${ }^{14,15}$ The picture however significantly varies from the figure of $1 \%$ in Europe and North America according to Boulton. ${ }^{16}$ The high cost and lack of well-trained multi-disciplinary medical personnel, facilities and standardized management protocols are possible contributory factors. Physicians also have an important role in the prevention, early diagnosis and management of diabetic foot complications. The physi- cian should carry out early risk assessment of the feet in DM patients which can be time consuming and when factored into the abysmally inadequate doctor-patient ratio in Nigeria will affect the depth of care a doctor can provide. According to $\mathrm{WHO}$ the density of physicians per 10,000 population is $4.0 .{ }^{17}$ This clearly will translate to very poor specialist attention. The seriousness of this crisis is underscored by current estimates that sub-Saharan Africa is part of the world that will experience the greatest rise in diabetes prevalence over the next 20 years. ${ }^{18}$ Other patient characteristics such as poor glycaemic control as measured by HbA1c, fasting blood glucose and even a single random blood glucose has been found to be strongly predictive of subsequent ulceration and amputation. ${ }^{19}$ In this study, the mean FBG, eABG and HbA1c were above acceptable limits for good glycaemic control. 
Similarly, comparable $\mathrm{HbA1c}$ results were documented by Dziemidok et al. ${ }^{20}$ and Chinenye et al. ${ }^{21}$ Ogbera et al .22 found a higher mean FBG of $11.6 \pm 4.7 \mathrm{mmol} / 1$ in $\mathrm{Ni}-$ geria while Kibirige et al. ${ }^{23}$ found a higher mean $\mathrm{HbA1c}$ of $9 \pm 2.9 \%$ in Uganda. Jbour et al. ${ }^{24}$ on the other hand found a lower mean $\mathrm{HbA} 1 \mathrm{c}$ of $7.4 \% \pm 1.4 \%$ in Amman Jordan. Jordan was ranked by the World Bank to be the number one health care services provider in the region and among the top five in the world, as well as being the top medical tourism destination in the Middle East and North Africa. ${ }^{25}$

Approximately 20\% of the participants with DFU had radiological features of osteomyelitis. This is comparable with $17 \%$ found in a UK based study by Bano et al. ${ }^{26}$, but lower than $34.4 \%$ found by Edo et al. ${ }^{27}$ The lower prevalence in the index study, compared to the other Nigerian based study could be due to the differences in the distribution of the ulcers according to Wagner's grading method. Grades 1 and 2 were the most common ulcer grades at presentation in the index study, as against grades 4 and 3 in the study by Edo et al. ${ }^{27}$

Spontaneous blister was the commonest cause of foot ulceration in this study, involving half of the study population. Unachukwu et al. ${ }^{28}$, and Edo et al. ${ }^{27}$ similarly found similar occurrences in their study $(51.7 \%$ and $52.46 \%$ respectively). The picture is further similar to the findings of workers in Nigeria. ${ }^{22,29}$ Though the patients reported the ulcers as resulting from spontaneous blisters, there remains a possibility that some of the ulcers may have resulted from unnoticed micro-trauma. Spontaneous blisters may also result from the use of inappropriate footwear; this was found to be the second commonest predisposing event for DFU in this study. Ill-fitting foot wears in patients with peripheral neuropathy may results in foot ulcerations in patients with insensate feet. Disordered foot mechanics and abnormal weight-bearing in different areas of the foot in patients with peripheral neuropathy also make the foot susceptible to ulceration while wearing shoes.

Of interest also, is the fact that self-inflicted burns due to thermal injury resulting from application of hot compresses to numb feet precipitated two cases of DFU recorded in this study. Thus, there is indeed a need to ensure that better focused education on appropriate foot wears, foot care and other harmful practices be intensified among these patients.

\section{Bacteriological pattern of diabetic foot ulcers}

In the present study, a total of 137 different microorganisms were isolated from the participants, with mixed gram-positive and gram-negative species; an average of 1.23 aerobic bacteria, 1.40 anaerobic bacteria and an overall average of 2.63 organisms per case. This is similar to the findings by Unachukwu et al. ${ }^{9}$ where cultures yielded an average of 2.3, but lower than the findings of Citron et $\mathrm{a}^{30}$ that yielded an average of 3.8 species per specimen; this may be as a result of the larger sample size in the US study. Improved culture techniques and use of nucleic acid-based techniques for isolating organisms is another plausible reason. Polymicrobial nature of diabetic foot infections have been observed in various studies within and outside the country. ${ }^{8,9}, 30$ The $71.2 \%$ polymicrobial isolates found in the present study is similar to the finding of $83.8 \%$ by Citron et al. ${ }^{30}$ Some studies suggest that the interactions of organisms within these polymicrobial mixtures lead to the production of virulence factors, such as hemolysins, proteases, and collagenases, as well as short-chain fatty acids, that cause inflammation, impede wound healing, and contribute to the chronicity of the infection. ${ }^{31,32}$ In such mixtures, biofilms that impede the penetration of antimicrobial agents into the infected site may also form. ${ }^{33}$ Thus, the presence of multiple species can have important clinical implications that should not be overlooked. In this study, gram-positive bacteria were the predominant pathogens with Staphylococcus aureus being the commonest aerobic isolate followed by Streptococcus pyogenes. Similarly, the predominance of Staphylococcus aureus has been demonstrated in many studies, within and outside the country. ${ }^{9-11,33,34-36}$ Predominance of gram-negative aerobes have been reported also by some few workers. ${ }^{37,38}$ These differences could be partly due to changes in the causative organisms occurring over time, geographical variations, or the types and severity of infection. Differences could further result from use of a relatively small number of specimens, and inadequate specimen collection techniques (which would fail to exclude superficial or colonizing organisms), poor handling techniques and poor preservation methods for anaerobic organism. ${ }^{39}$

Anaerobes were the predominant organisms cultured overall in this study with Bacteroides spp being the predominant organism, followed by Peptostreptococcus spp. This is in contrast with the findings of some other studies, which failed to isolate anaerobes in general. ${ }^{40-42}$ The failure to pick anaerobic bacteria in wounds may be due to several 
reasons. Compared with aerobic and facultative microorganisms, the culture, isolation, and identification of anaerobic bacteria is more time-consuming, labor-intensive, and expensive and is often deemed to be too demanding for many diagnostic microbiology laboratories. Since anaerobes are often perceived to die rapidly in air, the method of specimen collection and transportation to the laboratory is assumed to be critical for maintaining viability and for effective culture, in fact the yield of anaerobic organisms depends on the method of sample collection. Among those that did use appropriate methods, one study suggested that Bacteroides fragilis was the predominant anaerobic isolate ${ }^{43}$, while the predominance of Peptostreptococcus spp, followed by Bacteroides spp was demonstrated by Banoo et al. ${ }^{12}$ Least sensitivity was seen with the Penicillin (Ampicillin); this may be linked to the indiscriminate use of this older group of drugs in our society, even as seen among the participants in this study.

The gram positive and negative aerobic isolates showed high level of sensitivity to the quinolones particularly Levofloxacin, Norfloxacin, Pefloxacin and Ciprofloxacin but this was not a class effect as sensitivity to Ofloxacin was poor for both groups of microbes. All the anaerobic isolates were significantly sensitive to Clindamycin and Metronidazole. These findings are similar to the observations by Unachukwu et al. ${ }^{9}$ in Port Harcourt, Nigeria. This tends to suggest that antibiotic susceptibility may not have significantly changed over time across these close, but variable geographic locations. Similarly, despite wide geographical variation, butsimilar socioeconomic state, a study done in India, also reported a comparable susceptibility pattern. ${ }^{8}$

\section{Conclusion}

The study has demonstrated that the burden of DFUs is still huge among Nigerians living with diabetes mellitus. The bacteriological findings also shows that DM foot infections still largely remain polymicrobial however with likelihood of isolating many anaerobes if painstaking measures are taken to collect and handle the samples appropriately. A good sensitivity to common and available antibiotics was demonstrated but the abuse/inappropriate use of antibiotics remains a major issue to tackle among the patients. The sensitivity pattern shown here and previously reported by others should be a guide to empirical antibiotic usage among healthcare practitioners while waiting for sensitivity-guided treatment, which is the ideal practice. Intensified and focused educational initiatives on diabetes and the foot, early screening for diabetes complications and concerted efforts to improve glycaemic control may all go a long way in stemming the burden and consequences of DFUs and are therefore recommended.

\section{Conflict of interest}

None declared.

\section{References}

1. Ogbera AO, Ohwovoriole AE. The economic cost of diabetic foot syndrome. Afr J Endocrin metab. 2003;4:5963.

2. Kruse I, Edelman S. Evaluation and Treatment of Diabetic Foot Ulcers. Clinical Diabetes. 2006;24:93-96.

3. Ogbera AO, Fasanmade O, Ohwovoriole AE, Adediran O. An assessment of the disease burden of foot ulcers in patients with diabetes mellitus attending a teaching hospital in Lagos, Nigeria. Int J Low Extrem Wounds. 2006;5:244 $-249$.

4. "Issues in the New Poverty Report," This Day Live Newspaper 21, 2013. Available online at http://www. thisdaylive.com/articles/issues-in-the-new-poverty-report/137011/. Accessed 18/12/2014

5. Agu TC, Ojiaku ME. The indications for major limb amputations: 8 years retrospective study in a private orthopaedic and trauma centre in the south-east Nigeria. Journal of Clinical Orthopaedics and Trauma. 2016;7:242 247.

6. Solagberu BA. The scope of amputations in a Nigerian teaching hospital. Afr J Med Sci. 2001;30:225-227.

7. Laing P. The development and complications of Diabetic Foot ulcers, Am. J. Surg. 1998;176:11-19.

8. Chincholikar DA, Pal RB. Study of fungal and bacteriological infections of the Diabetic foot. Indian J Pathol Microbiol. 2002;45:15-22.

9. Unachukwu CN, Obunge OK, Odia OJ. The bacteriology of diabetic foot ulcers in Port Harcourt, Nigeria. Niger J Med. 2005;14:173-176

10. Akintewe TA, Akanji AO, Odusan O. Hand and foot ulcers in Nigerian diabetics: a comparative study. Trop Geogr Med. 1983;35:353-355

11. Emele FE, Izomoh ML, Alufohai E. Micro-organ- 
isms associated with wound infections in Ekpoma, Nigeria. West African Journal of Medicine. 1999;18:97-99

12. Banoo S, Shubha DS, Shashidhar V, Venkatesha D. Bacterial and clinical profile of diabetic foot patients. Ann Trop Med Public Health. 2012;5:69-73

13. Ajayi EA, Ajayi AO. Pattern and outcome of diabetic admissions at a federal medical center: A 5 year review. Ann Afr Med. 2009;8:271-275

14. Nyamu PN, Otieno CF, Amayo EO, Mcligeyo SO. Risk factors and prevalence of diabetic foot ulcers at Kenyatta National Hospital, Nairobi. East Afr Med J. 2003;80: 36-43

15. Boulton AJM. The diabetic foot. Medicine International. 1993; 271-274

16. Boulton AJ. The diabetic foot: a global view. Diabetes Metab Res Rev. 2000;1:2-5

17. WHO: Global Atlas of the Health Workforce. Global Health Workforce Statistics database, World Health Organization, Geneva. Available at http://www.who.int/ $\mathrm{hrh} /$ statistics/hwfstats/ (accessed on 25/03/17)

18. Wild S, Roglic G, Green A, Sicref R, King H. Global prevalence of diabetes: estimates for the year 2000 and projections for 2030. Diabetes Care. 2004;27:1047-1053

19. Gleckmen R, Morr DO. Diabetes related foot infections. Contemporary of Internal Medicine. 1994;6:57- 64

20. Dziemidok P, Szcześniak G, Kostrzewa-Zabłocka E, Paprzycki P, Korzon-Burakowska A. Current glycaemic control has no impact on the advancement of diabetic neuropathy. Ann Agric Environ Med. 2012;19:742-745

21. Chinenye S, Young E. State of Diabetes Care in Nigeria: A Review The Nig Health J. 2011;11:101-106

22. Ogbera OA, Osa E, Edo A, Chukwuma E. Common clinical features of diabetic foot ulcers: perspectives from a developing nation. Int J Low Extrem Wounds. 2008;7:9398

23. Kibirige D, Atuhe D, Sebunya R, Mwebaze R. Suboptimal glycaemic and blood pressure control and screening for diabetic complications in adult ambulatory diabetic patients in Uganda: a retrospective study from a developing country. J Diab Metab Disord. 2014, 13:40 doi:10.1186/2251-6581-13-40

24. Jbour AS, Jarrah NS, Radaideh AM, Shegem NS, Bader IM, Batieha AM et al. Prevalence and predictors of diabetic foot syndrome in type 2 diabetes mellitus in Jordan. Saudi Med J. 2003;24:761-764

25. Hazaimeh H. Jordan tops region as medical tourism hub. Jordan Times. Monday, Sep, 2008.
26. Bano I, Chaudhary WA, Hameed A. In vitro bacteriologic study and empiric antibiotic regimens for diabetic foot ulcers. Afr J of Microbiol Res. 2012;6:5568-5573.

27. Edo AE, Edo GO, Ezeani IU. Risk factors, ulcer grade and management outcome of diabetic foot ulcers in a Tropical Tertiary Care Hospital. Niger Med J. 2013;54:5963

28. Unachukwu C, Babatunde S, Ihekwaba AE. Diabetes, hand and/or foot ulcers: a cross-sectional hospital-based study in Port Harcourt, Nigeria. Diabetes Res Clin Pract. 2007;75:148-152

29. Eregie A, Edo AE. Factors associated with diabetic foot ulcers in Benin City, Nigeria. Niger Med J. 2008;49:911

30. Citron DM, Goldstein EJC, Merriam CV, Lipsky AB, Abramson MA. Bacteriology of Moderate-to-Severe Diabetic Foot Infections and In Vitro Activity of Antimicrobial Agents. J Clin Microbiol. 2007;45:2819-2828

31. Wall IB, Davies CE, Hill KE, Wilson MJ, Stephens P, Harding KG. et al. Potential role of anaerobic cocci in impaired human wound healing. Wound Repair Regen. 2002 10:346-353.

32. Yao Y, Sturdevant DE, Villaruz A, Xu L, Gao Q, Otto M. Factors characterizing Staphylococcus epidermidis invasiveness determined by comparative genomics. Infect. Immun. 2005;73:1856-1860

33. Vimalin HJ, Growther L. Studies on bacterial infections of diabetic foot ulcer. Afr J Clin Exper Microbiol. 2010;11:146-149

34. Dang CN, Prasad YD, Boulton AJ, Jude EB. Methicillin-resistant Staphylococcus aureus in the diabetic foot clinic: a worsening problem. Diabet Med. 2003;20:159-161 35. Lipsky BA, Berendt AR, Deery HG, Embil JM, Joseph WS, Karchmer AW. et al. Diagnosis and treatment of diabetic foot infections. Clin Infect Dis. 2004;39:885910 PubMed

36. Zubair M, Malik A, Ahmad J. Clinico-bacteriology and risk factors for the diabetic foot infection with multidrug resistant microorganisms in north India. Biology and Medicine. 2010;2:22-34

37. Gadepalli R, Dhawan B, Sreenivas V, Kapil A, Ammini AC, Chaudhry R. A clinico-microbiological study of diabetic foot ulcers in an Indian tertiary care hospital. $D i$ abetes Care. 2006;29:1727-1732

38. Shankar EM, Mohan V, Premalatha G, Srinivasan RS, Usha AR. Bacterial etiology of diabetic foot infections in South India. Eur. J. Intern. Med. 2005;16:567-570 
39. Orji FA, Nwachukwu NC, Udora EC. Bacteriological Spectrum of microbial flora in diabetic foot ulcers. Indian evaluation of diabetic ulcers in Nigeria. Afr J Diab Med. J Pathol Microbiol. 2008;51:204-208

2009;15:19-21

40. Hena JV, Growther L. Studies on bacterial infections of diabetic foot ulcer. Afr. J. Cln. Exper. Microbiol. 2010;11:146-149

41. Bansal E, Garg A, Bhatia S, Attri AK, Chander J.
42. Umadevi S, Kumar S, Joseph NM, Easow JM, Kandhakumari G, Srirangaraj S et al. Microbiological study of diabetic foot infections. Indian J Med Specialities. 2011;2:1217

43. Abdulrazak A, Bitar ZI, Al-Shamali AA, Mobasher LA. Bacteriological study of diabetic foot infections. J Diabetes Complications. 2005;19:138-141 